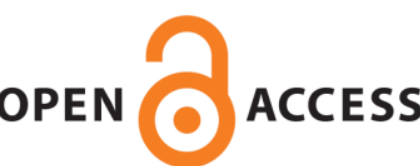

UWS Academic Portal

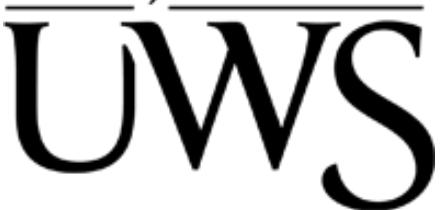

\title{
Emotional Intelligence and British expatriates' cross-cultural adjustment in international construction projects
}

Konanahalli, Ashwini; Oyedele, Lukumon

Published in:

Construction Management and Economics

DOI:

10.1080/01446193.2016.1213399

E-pub ahead of print: 19/08/2016

Document Version

Peer reviewed version

Link to publication on the UWS Academic Portal

Citation for published version (APA):

Konanahalli, A., \& Oyedele, L. (2016). Emotional Intelligence and British expatriates' cross-cultural adjustment in international construction projects. Construction Management and Economics, 34(11), 751-768.

https://doi.org/10.1080/01446193.2016.1213399

\section{General rights}

Copyright and moral rights for the publications made accessible in the UWS Academic Portal are retained by the authors and/or other copyright owners and it is a condition of accessing publications that users recognise and abide by the legal requirements associated with these rights.

Take down policy

If you believe that this document breaches copyright please contact pure@uws.ac.uk providing details, and we will remove access to the work immediately and investigate your claim. 


\title{
Emotional Intelligence (EI) and British Expatriates' Cross-Cultural Adjustment in International Construction Projects
}

\begin{abstract}
Today's internationalised business demands global mindset, intercultural sensitivity and the ability to skilfully negotiate through cross-cultural interactions. Therefore, the overall aim was to investigate the influence of Emotional Intelligence (EI) on cross-cultural adjustment (CCA) of British expatriates working on International Architectural, Engineering and Construction (AEC) assignments in Sub-Saharan Africa, China, Middle East and Indian Sub-Continent. Specifically, the causal relationship between EI and three facets of CCA i.e. work, general and interaction adjustment was explored. A sequential exploratory mixed methods design was adopted. These include extensive review of existing literature, eighteen unstructured interviews, and questionnaire survey of 191 British expatriates operating in twenty nine different countries from the four regions under investigation. Structural Equation Modelling (SEM) was used to assess the causal relationship between EI and CCA. Results show that EI accounted for 91\%, 64\% and $24 \%$ of the variance in work, interaction and general adjustment respectively. Overall the model was able to explain $60 \%$ variance in cross-cultural adjustment, suggesting that EI competencies play a huge role in facilitating an expatriate understand and adapt to host country culture. The findings would help decision-makers (HR managers) during expatriate selection process, in understanding that along with technical skills, it is the emotional competencies that are crucial in assisting expatriates adjust to foreign way of life.
\end{abstract}

Keywords: Emotional Intelligence (EI); Cross-cultural Adjustment; International Assignments; British Expatriates 


\section{INTRODUCTION}

Increased spending on infrastructure projects in emerging economies has had a tremendous influence on expatriation within the Engineering and Construction sector (PWC, 2008). International mobility not only helps to understand the complexities of international management but also provides competitive advantage through creating cosmopolitan managers who have the sensitivity for international opportunities (Liu \& Lee, 2008). As a result, researchers like, Bonache et al., (2001), Scullion and Brewster (2001) and Dowling et al., (2004) have devoted significant attention to investigating the topic of expatriation. These studies have predominantly focused on exploring the process of expatriate adjustment (Puck et. al., 2008) which involves uncertainty reduction by imitating or learning appropriate local behaviours and harmonising with the culture (Peltokorpi and Froese, 2009). In their pioneering study, Black and his colleagues conceptualised adjustment as a multi faceted concept as opposed to the dominant unitary view proposed by Oberg, (1960); Torbiorn, (1982) and Tung, (1987). Their widely accepted sociocultural model which encompasses three dimensions i.e. adjustment to the general environment, interaction with host nationals and work (Black et al., 1991) has received strong empirical support from McEvoy \& Parker, (1995); Shaffer et al., (1999); Palthe, (2004) and Waxin \& Panaccio, (2005).However, it should be noted that each facet of adjustment should be treated separately, since an expatriate could be well adjusted to one dimension but at the same time poorly adjusted to other (Bhaskar-Shrinivas et al., 2005).

Factors influencing an expatriate's adjustment can be related back to individual factors (self efficacy, relational and perception skills), organizational factors (organisation cultural novelty, social and logistical support), job role design (role clarity/ambiguity, discretion, novelty, conflict and overload) and non-work related factors (culture novelty, family/spouse adjustment) (Black et al., 1991). Black and his colleagues also make a distinction between anticipatory adjustment and in-country adjustment. During the anticipatory phase, pre-assignment organisational strategies that include, expatriate selection and cross-cultural training are believed to enhance expatriate adjustment (Lievens, et al., 2003). However, studies have shown that expatriate selection still continues to be unsystematic and most organisations continue to rely on technical skills and domestic track record as the criteria for selection (Morley \& Flynn, 2003; Sparrow et al., 2004). Based on previous studies Chew, (2004) compiled a list of selection criteria considered to be the predictors of expatriate success. These include technical ability, managerial skills, cultural 
empathy, adaptability, diplomacy, language ability, positive attitude, emotional stability, maturity and adaptability of family. Further studies have recognised the importance of Cultural Intelligence (CQ) (e.g. Alon \& Higgins, 2005) and Emotional Intelligence (EI) for overseas success (Mol et al., 2005). EI is defined as the capability to accurately and efficiently process information associated with emotions, recognition, construction, and regulation of emotion in oneself and others (Mayer and Salovey, 1995). In cross-cultural situations, an expatriate's EI is expected to help them to appropriately express their emotions; simultaneously monitor them possibly avoiding misunderstandings and conflicts (Lin et al., 2012), thus enabling him/her to face challenging situations more effectively (Arvil \& Magnini, 2007; Jordan et al., 2002). Despite abundant interest, to date very little research has been conducted to assess the impact of EI on cross-cultural adjustment with exception of Gabel et al., (2005), Lii \& Wong, (2008), Tan, et al., (2005), Koveshnikov et al., (2013) and Wetchler et al., (2015).

Furthermore, very few studies have investigated expatriation issues in AEC sector with exception of Konanahalli et al., (2014) who investigated the impact of Cultural Intelligence (CQ) on cross-cultural adjustment of British expatriate; Santosoa \& Loosemore, (2013) who investigated expatriation issues in Australian construction sector; Konanahalli et al., (2012) looked in to cross-cultural adjustment of British expatriates in Middle East; Puck et al., (2008) who investigated the adjustment of expatriates working in multi-national project teams and Zainol et al., (2013) and Zainol \& Abdul Aziz., (2010) who investigated a sample of Malaysian expatriates. To address the scarcity of research on expatriate management in AEC sector, the current study will specifically ascertain issues relating to British expatriates. A homogenous sample was primarily chosen to evade "distortion caused by expatriate samples where there is high cultural heterogeneity" (Kittler et al., 2011). The current sample is worthy of investigation particularly because, Great Britain has expatriated AEC professionals since the colonial times and it ranks as one of the strongest in the world.

The paper primarily explores the role of Emotional Intelligence (EI) in explaining work, interaction and general adjustment of expatriates. Therefore, studies conducted on EI were reviewed and interviews were conducted with British expatriates to identify individual level determinants of cross-cultural adjustment. The interviews helped address the research aim i.e. understanding the key individual competencies essential to deal with the dynamics of expatriation. The interviewee's highlighted the role of emotions as significant to the process of 
adjustment. Competencies like adaptability, flexibility empathy, self-reliance, self-management, stress management, communication etc. were highlighted which by large represent the concept of Emotional Intelligence (EI). Emotion based competencies were considered to be fundamental to resolving adjustment problems in a cultural context and effectively deal with tough work demands. This exercise was followed by discussion on theoretical framework and development of hypotheses. The paper then reported structural equation modelling (SEM) by analysing 191 questionnaire responses from British expatriates operating in the four regions of investigation. The findings of the current study contribute to literature on expatriate management within the AEC sector by presenting a framework that confirms the significance of EI for cross-cultural adjustment. Suggesting that discovering the competencies to effectively and appropriately deal with cross-cultural assignments could help AEC organisations develop robust selection and training strategies. Lacking foresight and appropriate strategies, organisations can hinder the effectiveness of the assignment by producing frustrated, disillusioned, discontented expatriate staff (Mammadov \& Poss, 2010).

\section{LITERATURE REVIEW}

\section{Cross-cultural Adjustment (CCA)}

The U-Curved Theory (UCT) was one of the earliest and widely accepted theories that attempted to explain the degree of expatriate's adjustment. Subsequent studies found that the level of anxiety differed with each individual (Church, 1982), hence social learning theory was then employed to explain adjustment from the perspective of individual learning through social interaction during acculturation (Black \& Mendenhall, 1991). Here, adjustment is defined as a process of understanding and incorporating behaviours, values and beliefs of the host country culture in the perspective of the one's own culture of origin (Constantine et al., 2004). Black and his colleagues conducted a pioneering study in the field of expatriate adjustment and proposed a theoretical framework by integrating domestic and international adjustment literature. They conceived socio-cultural adjustment as a three-dimensional phenomenon with the following facets:

\section{- Work Adjustment}


It is the degree to which an expatriate feels comfortable about their new job environment and its requirements (Shimoni et al., 2005). Due to similarities in procedures, policies and requirements on international operations, work adjustment is considered to be the easiest of the three facets (Black et al., 1992).

\section{- Inte raction Adjustment}

It involves the comfort achieved in interacting with host nationals in both work and nonwork situations. It is considered to be most difficult of the three facets, because it is during cultural interaction that differences in values, assumptions and belief's become apparent (Stroh et al., 2005).

\section{- General/ Non-social Adjustment}

It is the overall reaction/adaptation to living in the new culture (Black, 1988). It includes factors such as housing conditions, transportation, entertainment, health care, and cost of living (Black and Stevens, 1989).

Though this model has been well received by researchers in expatriate management, it has been critiqued for its theory driven approach and unsystematic development of scale items which are uni-dimensionally measured on an adjusted- unadjusted scale (Haslberger, 2008). To address this issue, the adjustment measures to suit the context of AEC assignments were reviewed and revised. Further reliability and validity tests were performed to ensure that the measures are robust.

\section{Emotional Intelligence (EI)}

The term EI was originally coined by Salovey and Mayer (1990) who conceptualised it as an enduring personal trait/ability. They defined it as a subset of social intelligence that involves the ability to monitor one's own and other's feelings and emotions, to discriminate among them and to use this information to guide one's thinking and actions (Salovey and Mayer, 1990). This model which defines EI as an ability that involves cognitive processing of emotional information is criticized for its 'narrow measures' that centre on perceiving, understanding and regulating emotions (O’Boyle et al,, 2010). Later, Goleman (1998) who actually popularized EI conceptualised it as a mixed-trait model encompassing personality traits, motivational and social 
skills. Accordingly, EI begins with the capacity of recognizing our own feelings (self-awareness) and those of others (social awareness). With such heightened awareness of self, it develops abilities for managing emotions effectively in oneself (self-management) and others (social skills) (Goleman, 1998). The Emotional Intelligence framework (Table 1) put forward by Cherniss and Goleman (2001) grouped twenty competencies under four broad dimensions of Emotional Intelligence.

\section{Insert Table 1}

As such, there is no universally accepted definition of this complex construct (Higgs and McGuire, 2001). However, a meta-analysis by O'Boyle et al., (2010) supported the "mixed-trait models" for its ability to predict performance across a wide range of occupations compared to ability-based model which is often better able to predict performance in jobs higher in emotional labour (cited by Emmerling and Boyatiz, 2012). Since the aim was to investigate the potential role of emotional competencies in explaining British expatriates' adjustment on international assignments, and given that adjustment dictates secondary outcomes of performance and tenure intentions, mixed EI model developed by Goleman and Boyatzis's was deemed most appropriate. Additionally, the measures developed by the mixed model encompass a wide array of social skills and abilities which are better at predicting job performance (Cherniss, 2010; Ashkansay and Daus, 2005).

\section{THEORETICAL FRAMEWORK AND HYPOTHESES DEVELOPMENT}

Given that international assignments are inherently costly, the research on cross-cultural adjustment (CCA) of expatriate has gained significant attention. Generally, the results of these studies acknowledge inability of expatriate to adjust to new setting as main cause for assignment failure (Min et al., 2013). On the contrary, an adjusted expatriate is well versed and maintains behaviours appropriate to the new environment, which in turn dictates secondary outcomes of performance and tenure intentions (Kraimer \& Wayne, 2004).

According to Bhawuk and Brislin (1992), emotion based competencies like, genuine interest in other cultures, sensitivity to notice cultural differences, and willingness to modify the ir behaviour are essential to be effective in other cultures. This is especially true when the socio- 
cultural differences (level of development, education, business, cultural values etc.) between the home and host nation are significant. In this case, British expatriates from individualistic culture experience high degree of emotional labour when immersed in collectivist cultures (Indian subcontinent, Sub-Saharan Africa, Middle East and China). Ego focused emotions (anger, frustration, and pride) which are typical of individualists are diametrically opposite to othersfocused emotions characteristic of collectivists (eg. empathy, appreciation etc.) (Tan et. al., 2005). As such, individualists experience emotional conflict when the host culture requires them to put the needs and wants of the group before their own self (Tan et al., 2005). This ambiguity surrounding cultural issues/differences has the potential to create substantial misunderstandings during cross-cultural encounters (Dolan and Kawamura, 2015). Therefore, Lin et al., (2012) aptly suggest that appropriate emotional expression holds the key to reducing psychological stress and adjustment problems. An expatriate's EI would help them to recall cross-cultural knowledge stored in their memory (Susanto and Rostiani, 2012), appropriately express their emotions, simultaneously monitor them possibly avoiding misunderstandings and conflicts (Lin et al., 2012), thus enabling him/her to face challenging situations more effectively (Arvil \& Magnini, 2007; Jordan et al., 2002). Furthermore, utilization of emotions is believed to motivate expatriates to be persistent and avoid stereotyping when making judgement about the host country environment, which is culturally less familiar (Koveshnikov et al., 2014). Therefore, this ability to understand and manage the emotional reactions in oneself, and those of others and to effectively adapt in culturally diverse settings, have been increasingly recognized as critical elements that influence adjustment (Kumar et al., 2008).

Living and working overseas further EI competencies like, understanding one's own and others' mood, emotion (Yamazaki and Kayes, 2004), adaptability and communication (Crowne, 2013). Hence, it would be appropriate to suggest that EI is a critical competency that would facilitate adjustment to all dimensions i.e. work, interaction and general conditions on international assignments.

\section{Insert Figure 1}

As a result, it is proposed that;

H1: Emotional Intelligence has a positive and significant influence on General Adjustment. 
H2: Emotional Intelligence has a positive and significant influence on Interaction Adjustment.

H3: Emotional Intelligence has a positive and significant influence on Work Adjustment.

\section{RESEARCH METHOD}

The complexity associated with the expatriation of British AEC professionals required the investigators to adopt a combination of research strategies to increase one's understanding of the complex social phenomena (Greene \& Caracelli, 1997). Mixed methods design was adopted since it not only offered an new way of conceiving research, but produced more robust measures of association whilst acknowledging the reality that multiple paths to meaning exist (Wheeldon, 2010). Quantitative data was useful for explanation and qualitative data complemented quantitative data to portray the real story behind the statistics (Dobson, 2002).

As a result, sequential exploratory mixed methods design was used to deal with the underresearched topic of expatriate adjustment in AEC sector. The design unfolded in three phases. Phase one was characterised by extensive review of literature from various fields including construction management to identify the relevant factors. In the second phase eighteen unstructured interviews were conducted with organizational British expatriates who were managing or had previously managed their parent company's AEC operations in Sub-Saharan Africa, Middle East, China and the Indian sub-continent. The interview data was analysed using cognitive mapping through Banaxia Decision Explorer. The data extracted from the qualitative analysis informed the development of the theoretical framework and questionnaire.

\section{SAMPLE PLAN}

The data was collected during December 2011 and March 2012. Employing criterion sampling technique a list of international British companies operating in above mentioned regions were obtained. Here, the members of the target population who meet some special criteria were selected (Teddlie \& Yu, 2007); in this case British expatriates managing or have previously managed their parent organisation's international AEC operations. This sampling strategy helped to gain an insight into British expatriate population within specific locations. Human Resource managers of the international British AEC organisations operating in the four regions of 
investigation were contacted and approval was sort for participation. Participants were also chosen by adopting snowball sampling technique. Here the respondents were requested to assist with recruiting other expatriates who meet the eligibility criteria (Spreen, 1992). This technique helped to effectively engage the hard to access British expatriate group (Hall, 2008).

\section{DATA COLLECTION AND QUESTIONNIARE DESIGN}

The target population include British expatriates from the AEC sector who had been sent on international assignments by their parent company. Prospective respondents were contacted to complete self-completion email survey. The respondents were screened to ensure that they fulfilled the eligibility criteria. The questionnaire was divided into four sections, Section A was designed to gather demographic information, whereas Section B the main body of the questionnaire consisted of 25 variables used to measure Cross-cultural Adjustment (CCA) and Emotional Intelligence (EI). Here participants were requested to state their level of agreement or disagreement on a five-point Likert scale with items ranging from "strongly disagree" to "strongly agree." The statements referred to in this paper were part of a more extensive questionnaire which covered additional issues relating to international assignments. Multiple item scales for CCA and EI were pinched from well-developed instruments in the literature but modified to reflect the context of investigation and achieve strong alignment. The variables in Section B were quantified using the following measurement scales: -

\section{Emotional Intelligence (EI)}

18 competencies of the Emotional Competence Inventory 2.0 (ECI) have been used to investigate the Emotional competencies of British expatriates. The ECI-2.0 has its genesis from three sources that include; the emotional competencies identified by psychologist Daniel Goleman, Hay/McBer's Generic Competency Dictionary (1996) and Dr. Richard Boyatzis's Self-Assessment Questionnaire (SAQ) (Hay Group, 2005). It is a multi-rater instrument designed to assess an individual's behavioural indicators of EI. The emotional competencies are organised along four clusters namely; Self-awareness (SEA), Self-management (SEM), Social awareness (SOA) and, Relationship Management (RM). 
The original ECI-2.0 contains seventy two items i.e. four items are used to measure each of the eighteen competencies. It can be assessed by the individual him/herself and others. It normally takes about 30-45 minutes to complete the questionnaire. For the current study, the eighteen competencies identified by the Emotional Intelligence frame-work have been used. Communication competency which was previously used in ECI-1.0 was dropped for ECI-2.0 to merely achieve brevity and the authors believed that this competency did not differentiate outstanding performance for a number of professional samples. This competency has been included within the current scale for the very reason that emotions are inherently communicative and that communication is an essential aspect to the process of emotional experience (Andersen and Guerrero, 1998). This particular competency i.e. give-and-take of emotional information is one of the most important functions to master in an increasingly competitive international project environment.

Therefore, the scale contains three items each, to measure Social awareness (SOA) and Selfawareness (SEA), six items to measure Self-management (SEM) and seven items to measure Relationship Management (RM). Cronbach's $\alpha$ for SEA, SEM, SOA, RM and overall scale were 0.71, 0.81, 0.73, 0.88 and 0.93 respectively. Refer to Appendix A for the items used to measure EI.

\section{Cross-cultural Adjus tment}

To measure expatriate's socio-cultural adjustment a six item scale was developed by adapting Hemmasi et al's scale for cultural and work related adjustment. Since the existing scales didn't precisely align with the study's objectives, the original scale was customized to appropriately capture the underlying construct and reflect the specific aspects of AEC assignments highlighted by the expatriates during the interviews.

The scale contains two items each to measure general, work and interaction adjustment. Cronbach's $\alpha$ for general adjustment, interaction adjustment, work adjustment and overall scale were $0.83,0.52,0.65$ and 0.78 respectively. Refer to Appendix A for the items used to measure this construct. 


\section{ANALYSIS}

Of 197 received questionnaires, only 191 responses were valid. Descriptive statistics were computed on the respondents' profiles like age, gender, marital status, job title and experience (including international) in the industry. Among the 191 respondents, the highest proportion i.e. $94 \%$ were males and only $6 \%$ were females. Majority of the participants $64.4 \%$ were married and in the age group of 30-54 years. Respondents holding the title of regional directors accounted for $23.65 \%$ whereas, $31.9 \%$ held other titles including, Project Director, Construction Manager, Commercial Manager, Technical Manager, H\&S Manager, Senior Procurement Manager, etc. representing a typical sample of the construction industry.39.79\% of the respondents had an industrial experience of 26+ years whereas, $16.23 \%$ had an experience of 21 to 25 years.

In terms of their international exposure, bulk of the respondents i.e. $69.63 \%$ had pervious international experience. $83.75 \%$ were reporting their current assignment and $16.75 \%$ were repatriates reporting their past assignment experiences. The expatriates were stationed in a total of 29 countries that include; Azerbaijan, Bahrain, Bangladesh, Botswana, China, Egypt, Hong Kong, India, Kuwait, Macau, Mauritius, Mozambique, Nigeria, Oman Pakistan, Qatar, Saudi Arabia, Sierra Leone, South Africa, South Sudan, Sri Lanka, Taiwan, UAE, Uganda, Zambia and Zimbabwe. The responses in Sub-Saharan Africa, China, Indian Sub-continent and Middle East were $20.94 \%, 20.4 \%, 21.47 \%$ and $37.17 \%$ respectively. The descriptive statistics results suggest that the expatriates had significant experience and were better placed to provide accurate information about their expatriation. In order to address the common variance issue, the Harman's single factor test was conducted (Podsakoff et al., 2003). Here un-rotated principal component factor analysis was performed in SPSS using the entire dataset. The results suggested the existence of more than one factor which implies it would be appropriate to conclude that it is unlikely that the data is affected by common method bias. Next Spearman's correlation for facets of emotional intelligence and cross-cultural adjustment were computed, refer to Table 2. In this non-parametric test of Spearman's rank correlation medians are compared which is appropriate for non-parametric data (Bryman \& Cramer, 2002; Jamieson, 2004).

\section{Insert Table 2}




\section{STRUCTURAL EQUATION MODELLING (SEM)}

For the present study Structural Equation Modelling (SEM) was used to analyse the relationship between observed (directly measured) and latent variables (not directly observable), since it encourages confirmatory rather than descriptive approach to data analysis. First the measurement model was tested and validated followed by the assessment of the structural model (Hair et al., 2006; Kline, 1998). The rationale behind adopting this hierarchy was to avoid building a structural model with poor measures. The researchers used AMOS 17 software programme to test the fit of both the measurement and the structural model. The measurement model indicated how latent variables are measured in terms of observed variables; whereas, a structural model articulates relationships among the latent variables (Islam, et al., 2005). Since the items used to measure the constructs were adapted and modified from previous instruments, it was deemed appropriate to conduct a validity check to assess the internal consistency, convergent and discriminant validity of the constructs. Construct reliability and validity checks were performed to validate the measurement model, whereas a variety of fit indices were used to assess the structural model. Construct validity is the extent to which the constructs or a set of measured items actually reflect the theoretical latent construct those items are designed to measure (Hair et al, 2006). Face, convergent and discriminant validity tests were performed to evaluate construct validity whereas, Construct reliability analysis of the measurement variables was assessed through Cronbach's reliability test and composite reliability coefficient.

\section{Construct Validity}

Face Validity was achieved through extensive literature review, interviews and pilot exercise which mainly helped to assess the validity of the constructs. For the current study, the questionnaire items were reviewed by five British expatriates and five academicians.

Convergent validity is a measure of internal consistency which is estimated to ensure that the measurement variables provide true measures of the respective latent variables in entirety. It can be examined with reference to standardised factor loadings and Average Variance Extracted (AVE). Convergent validity is said to be satisfied for measurement models whose factor loadings are significant at an appropriate level (Anderson \& Gerbing, 1988). AVE for each construct estimates the amount of common variance among the latent construct indicators. Variance 
extracted of greater than 0.50 suggests satisfactory convergence validity (Hair et al., 2006). Hulland (1999) recommends AVE values between 0.16 - 0.25 for new adapted/ developed scales.

Discriminant validity represents the extent to which a construct is truly different from other construct (Hair et al., 2006). To examine discriminant validity of a measurement model, correlations amongst latent constructs are examined. High value correlations exceeding 0.9 or 0.85 are noted to be problematic.

Construct Reliability of the measurement variables is assessed through Cronbach's $\alpha$ reliability test and composite reliability coefficient. Nunnally (1978) recommends a Cronbach's alpha coefficient of 0.7 , but values between 0.5 to 0.6 are considered to be acceptable for preliminary research (Nunnally, 1967). Cronbach's $\alpha$ above the minimum of 0.35 for a sample of 244 is suggested by Hair et al., (2006). Composite Reliability (CR) is a means of assessing internal consistency of the items of latent variables (Chin, 1998). Raine-Eudy (2000) recommends a cut off value of 0.5 . It is computed as,

$$
C R=\frac{\left(\sum_{i=1}^{n} \lambda_{i}\right)^{2}}{\left(\sum_{i=1}^{n} \lambda_{i}\right)^{2}+\left(\sum_{i=1}^{n} \delta_{i}\right)}
$$

Composite reliability is computed from the sum of factor loadings $(\lambda i)$, squared for each construct and the sum of the error variance terms for a construct $(\delta i)$ using the above formula (error variance is also referred to as delta).

\section{Structural Model}

After assessing the measurement model, the fit of the model to the sample data was evaluated. Reporting a number of fit indices is considered to be necessary since different indices reflect a special aspect of model fit (Sivo et al, 2006). The commonly employed fit indices are; Chisquare $(\chi 2) /$ degrees of freedom (df), goodness-of-fit index (GFI), adjusted goodness-of-fit index (AGFI), Bentler comparative fit index (CFI), incremental fit index (IFI), root mean square error or approximation (RMSEA), non-normed fit index (NNFI) and Comparative Fit index (CFI). Table 3 indicates the recommended fit values for the various indices. In line with the 
recommendations of researchers, the present study has included multiple fit indices like, RMSEA, CFI, GFI, CMin/df ( $\chi 2 / \mathrm{df})$, TLI, IFI and P-Close to examine the overall model fit. Insert Table 3

\section{First and Second Order CFA}

Both the concepts used in the current study are multidimensional constructs. Suggesting that structure of both the models involves a second order construct whereby a latent variable is represented by three/four latent variables (See Figure 2). To confirm the factor structure of both the constructs, a confirmatory factor analysis (CFA) was conducted. According to Kenny (2012), this second order approach helps to preserve multi-dimensional constructs, reduces collinearity by having the causality work through a single second-order factor and helps to understand how strongly the first-order factors load on the hypothesized second-order factor.

\section{Measurement Model Assessment}

The nineteen EI items were subjected to first and second order CFA. The first order measurement model showed good fit and the second order measurement model further improved model fit.

\section{Insert Figure 2}

\section{Insert Table 4}

The standardized factor loadings for the second order model were substantially high ranging from 1.04 to 0.92 and all were significant at $\mathrm{p}<0.001$. These indicators provide support for the convergent validity of the model. The measurement model has established an acceptable level of reliability as both Cronbach $\alpha$ and CR values are well above the recommended levels (Table 4). The Spearman's correlation analysis (Table 2) suggests that though the EI sub constructs highly correlate, but they do not correlate perfectly. Hence discriminant validity for the EI construct has been established.

Similarly the second order CCA model has several significant aspects. Robust loadings on most of the first and second order factors suggest that they provide valid measures of the factors on 
which they load. This second order model showed excellent model fit (Table 5). The standardized factor loadings for each indicator are listed in Table 4. The results suggest that not only did the indicators load very well on their respective factors but all the loadings in the model were significant since, all path coefficients are significant at $0.001(* * *)$ level. This implies that the current model has been successful in establishing the relationship between WA, IA, GA and CCA. Table 4 shows the construct reliability and AVE for all the latent constructs of adjustment. All the three sub components of cross-cultural adjustment exceeded the recommended level of 0.50 for composite reliability (CR) which indicates that all three constructs are internally consistent. The calculation of AVE for one of the sub-constructs did not meet the minimum value of .50 i.e. IA (0.45) is slightly below the threshold level. Hair et al., (1998) argued that it is possible to have a poor variance extracted, yet have high construct validity.

Since Construct Reliability (CR) has been established and all the factor loadings are significant, it therefore confirms convergent validity of CCA. Discriminant validity, achieved through the correlation analysis suggested that WA, IA and GA were not perfectly correlated, thus establishing discriminant validity for CCA. The results confirm that both EI and CCA constructs demonstrate sufficient validity and reliability.

\section{Structural Model Assessment}

An examination of the fit indices for the first and second order models for EI and CCA suggest that the model fits the data extremely well (Table 5). The next step was to test the hypotheses. The SEM results supported all three main hypotheses, indicating statistically significant paths. The data analysis confirmed that EI could be a significant predictor of an expatriate's crosscultural adjustment. The structural model generated very good fit indices (See Table 5). The ratio of $\chi^{2} /$ degree of freedom is 1.741 and the GFI index value of 0.841 . Though the value of GFI is slightly below 0.90 it was deemed acceptable in accordance with the recommendations of Grandzol and Gershon (1998) who reported GFI of 0.795 as marginally accepted. The RMSEA value of 0.062 at $\mathrm{p}<0.05$ indicates that the final model cannot be rejected at a high level of confidence. Furthermore, all other essential indices provide evidence that the fit between the measurement model and the data is certainly acceptable.

\section{Insert Table 5}


The square multiple correlations $\left(\mathrm{R}^{2}\right)$ which corresponds to the amount of variance in each endogenous latent variable accounted for by the independent latent variables, were calculated. Among the individual components of EI; SEA, SEM, SOA and RM explained 81\%, 95\%, 99\% and $77 \%$ variation in EI respectively. The $\mathrm{R}^{2}$ for the three endogenous adjustment variables ranged from 0.24 to 0.91 (Figure 3). EI explained 91\% variation in work adjustment, 64\% variation in interaction adjustment, and $24 \%$ variation in general adjustment. Overall, the model had an $\mathrm{R}^{2}$ of 0.60 , which indicated that EI explained $60 \%$ of variance in CCA.

\section{Insert Figure 3}

\section{DISCUSSION OF FINDINGS}

The confirmatory factor analysis (CFA) results substantiate that EI is able to explain crosscultural adjustment among British AEC expatriates. These findings attested the validity of EI for expatriates in line with the findings of Gabel-Shemueli \& Dolan (2011) and Koveshnikov, et al., (2013). Based on the values in Figure 3, it can be concluded that social awareness (SOA) emerged to be the most influential component of EI followed closely by self-management (SEM), self-awareness (SEA) and relationship management (RM). The relatively lower contribution of relationship management/social skills could be explained by the fact that due to time pressure which is very apparent on construction related activities, expatriate managers may engage in fewer growth activities i.e. provide feedback and guidance to their sub-ordinates which in turn impacts on their working relationships with team members (Lindebaum and Fielden, 2011).

However, EI as a whole was able to explain high amount of variance in work and interaction adjustment, contributing $91 \%$ and $64 \%$ of $\mathrm{R}^{2}$ respectively. Based on the results, it would be relevant to suggest that individuals high on emotional quotient were more likely to perceive context-driven emotion patterns and therefore were better adapted to these situations than those with low EI (Lillis \& Tian, 2009). The findings are consistent with previous studies in domestic context which demonstrate EI to be a significant predictor of work performance. Following is an elaborate discussion on how EI contributes towards each aspect of cross-cultural adjustment. 


\section{EI and Work Adjustment}

On international assignments, work domain warrants special attention because organizations being output oriented tend to focus on the work performance as a measure to assess success on international assignments. Also due to the stress, uncertainty and anxiety associated with unfamiliar situations, expatriate work demands higher reasoning ability than domestic work (Shin, et al., 2003). On a whole, the results (Figure 3) reveal that with a $\beta$ co-efficient of $0.95 \mathrm{EI}$ had strongest impact on work adjustment compared to interaction or general adjustment.

With a Spearman's correlation coefficient $r_{s}($ SEA and WA $)=0.43 @ p<0.01$ and factor loading $(\beta)=0.99$, the results suggest that the social awareness dimension of EI would help an expatriate to interact more effectively with others and eventually achieve organizationally desired outcomes. This component of EI is particularly important for AEC industry (in line with findings of Cherniss \& Goleman, 2001), for it could assist in understanding a client's unstated needs, demands and match them with services like designs, concepts, plans etc. Confirming our finding that socially aware expatriates are better placed to adjust to work on international postings.

Emotional self-management emerged to be the second most important EI sub-construct with a factor loading $(\beta)$ of 0.98 and Spearman's correlation coefficient of $r_{\mathrm{s}}($ SEM- WA $)=0.614 @$ $\mathrm{p}<0.01$. Given that AEC related assignments are inherently stressful and fraught with uncertainty, self-monitoring skills are highly valued to help individuals to be emotionally in control and successfully navigate through stressful situations (Mathews et al., 2002). The other two dimensions of EI; Self-awareness and Relationship management also proved to be significant contributors. For instance, self-awareness skills helped to deal with negotiations, conflicts, disputes between different parties, to know what generates his/her her emotions and how it influences others. Self-confidence a sub component of self-awareness helped an expatriate to be persistent when he/she encountered problems, opening avenues for positive adjustment outcomes. Relationship management skills in the context of $\mathrm{A} / \mathrm{E} / \mathrm{C}$ related assignments facilitated building long-term relationships with multi-cultural clients, government officials, coworkers, suppliers, customers etc. which eventually helped to meet performance expectations of the parent company. 


\section{EI and Interaction Adjustment}

After work adjustment, EI had significant influence on interaction adjustment with a $\beta$ coefficient of 0.80 and $\mathrm{R}^{2}=0.64$ highlighting that EI explains the competencies needed for successful interactions with host nationals on a day today basis. With a Spearman's correlation coefficient of $\mathrm{r}_{\mathrm{s}}(\mathrm{SEA}-\mathrm{IA})=0.439$ @ $\mathrm{p}<0.01$ and a factor loading $(\beta)=0.99$ (Figure 3), the results reiterate the importance of social awareness competency for cultural interactions. Findings of the current study are consistent with that of Koveshnikov, et al., (2014) and Gabel et al. (2005) who emphasised the positive influence of social awareness competency on expatriate's interpersonal interactions in work and non-work situations.

Furthermore, with a Spearman's correlation coefficient of $r_{s}($ SEM- IA) $=0.512 @ p<0.01$ and factor loading $(\beta)=0.98$ the results highlighted that self- management competencies did provide greater ability to engage, suggesting that such individuals develop relationships at work with people from different cultural backgrounds. Being flexible in their behaviours, they quickly adjust and fit into the demands of the situation. For this very reason, self-management skills are likely to improve the interactions within diverse groups (Lloyd \& Härtel, 2003). Lacking in this quality along with inability to connect to the host country culture, gaps in social support and social isolation, there could be high probability that the expatriate would succumb to various forms of wrong addictions. A sense of humility (by product of self-awareness) is also an important competency contributing towards successful intercultural interaction (Bird \& Osland, 2004). Overall, the findings suggest that self and socially aware expatriates are better placed to adjust and work in multi-cultural teams.

Among all the EI competencies one would expect relationship management skills to contribute significantly towards interaction adjustment, since social skills help to motivate employees to excel, successfully negotiate conflicts, effectively participate, lead multicultural teams (Moran \& Riesenberger, 1994) and perform effectively (Harrison \& Shaffer, 2005; Mol et al., 2005). Given the importance of social interaction and relationship development for cross-cultural adjustment, social skills work through any cultural difference facilitating adjustment to the new culture and promoting positive relationships with the locals (Shin, et al., 2003). A study by Kayes et al., (2005) involving western expatriates revealed that relationships established with the locals provided expatriates with immense opportunities to learn and absorb the new culture. 


\section{EI and General Adjustment}

The results reveal that overall EI had the least amount of influence on general adjustment with a factor loading $(\beta)$ of 0.49 and $R^{2}=0.24$. Nonetheless, the results confirm the relevance of emotions and EI to cope with complexity of the new cultural context. Since British expatriates who participated in the data collection phase were posted in regions that were diametrically opposite their home country, the need to acquire or display emotional and cross-cultural skills was even higher. The results indicate that EI competencies could to some extent diminish the cultural differences between the home and the host country thereby facilitating better adjustment (Gabel et al., 2005). Good general conditions along with better healthcare facilities within host country tend to influence the adjustment of spouse and family and thereby have a positive impact on the expatriate like, increase the probability for a longer stay (Garonzick et al., 2000).

In all these situations, expatriates need to possess the ability to pick themselves up' when things become difficult and remain focused on the task to be completed (Ramgutty-Wong \& Dusoye, 2011). Self-management skills like, the ability to adapt and keep disruptive emotions in check could help expats to cope with uncertainty in the new environment. Whereas, self-confidence could not only reduce cultural shock (Earley \& Ang, 2003) but help the expatriate to be persistent in stressful situations, opening avenues for positive adjustment outcomes. Finally, interpersonal relations developed with host nationals' act as a rich source of information helping expatriates understand intricacies and adjust well to the host country.

\section{CONCLUSION}

An insight into how EI competencies can facilitate the expatriate process of adjustment to host country were examined through a representative sample of 191 British expatriates from the AEC sector. The sampled British expatriates were operating in twenty nine different countries across the four regions Sub-Saharan Africa, China, Middle East and Indian Sub-Continent. The focus was on the overall influence of four-dimensional EI construct on work, general and interaction adjustment. A hierarchical SEM model was constructed consisting of several paths based on hypotheses that were developed through comprehensive literature review and expert interviews. EI model accounted for $91 \%, 64 \%$ and $24 \%$ of the variance in work, interaction and general 
adjustment respectively. These results clearly demonstrate the critical contribution of emotions to deal with cross-cultural contexts.

Specifically, EI positively influenced an expatriate's adjustment to work and interaction in the new environment supporting the findings of Gabel et al., (2005) and Koveshnikov, et al., (2013), and contrasting Lii and Wong (2008) who found no impact of EI on cross-cultural adjustment. A study by Lindebaum and Jordan (2012) also supported that EI would be particularly beneficial for managers who deal with tasks that are interpersonal in nature. The findings yield valuable insights and implications for theory as well as practice. Theoretically, the present study is the first to investigate this emerging concept of EI in the context of the AEC industry by exclusively recruiting British expatriates. The newly modified scales for EI and CCA which have established consistency could be utilised as an instrument to gauge assignment outcomes by human resource managers and researchers alike.

From the practical perspective, findings support a growing body of researchers who are calling for EI to be considered as tool both for selection and training for expatriates within AEC organizations. These findings can inform $\mathrm{HR}$ practices and strategies to improve expatriate effectiveness through various support strategies and selecting the right person for the job. Consistent with previous research studies (e.g. Jassawalla et al., 2004 and Gabel et al., 2005), it is recommended that international British AEC organizations intending to export skills, work practices through expatriates to their foreign operations could consider EI as one of the criteria when selecting individuals for international assignments along with personality traits, Cultural Intelligence, Social intelligence etc. Nonetheless, some adjustment time must be provided to assist the assignees in overcoming hurdles and integrating themselves into the new work and cultural environment.

EI tends to develop with experience (Mayer et al., 1999). Suggesting that EI can be both cultivated (through training) and assessed in potential candidates. EI assessment could take various forms like peer review surveys and face-to-face interviews (answer various situational and behavioural questions) (Goleman, 1998). EI competencies can be further developed through measuring the existing EI levels and identifying the one's that need improvement and then developing a personalised competency development plan (Pryke and Symth, 2006). For international assignments, EI training could be clubbed with cross-cultural training (Musten et 
al., 2003). The enhanced understanding of the impact of EI on British expatriates can greatly help to effectively and resourcefully operate in those unfamiliar environments of international assignments.

In addition, the AEC sector in general could benefit by further exploring the field of individual psychology, given that the industry is struggling to develop leadership and management capabilities (Firth, 2015). Studies by Butler and Chinowsky, (2005) and Sunindijo, (2007) have confirmed the relationship between EI and leadership traits, demonstrating that EI and transformational leadership skills can be key enablers that could transform the sector. Individuals with such enhanced capabilities could address the existing challenges by bringing together diverse groups to successfully deliver projects benefitting a wide range of stakeholders, be it the individual him/herself, the team, the client, and the industry as a whole.

Obviously there are limitations that need to be considered when interpreting the findings. The first limitation is associated with small sample size due to limited contacts and cross-sectional design in the data collection. Secondly, the data has been collected from British expatriates working in twenty nine of the seventy seven countries that constitute the four regions under investigation. Owing to which, there could be some issues with regards to the generalizability of the findings for British expatriates working in these four regions. Third limitation could be with regards to self-reporting questionnaires i.e. tendency of participants to highlight their situation more positively than it actually is (Koveshnikov, et al., 2013). Further, the scales utilised for Emotional Intelligence (EI) and Cross-cultural Adjustment have undergone scrutiny and haven't been adopted in their entirety. Future research needs to further delve into explicating the impact of EI on expat performance on international assignments. As recommended by Wechtler et al., (2015) and Koveshnikov, et al., (2013) various demographical variables like age, gender, previous international experience etc. could be used to moderate the relationship EI and adjustment in order to draw more robust conclusions. 


\section{APPENDIX A}

The items used to measure Emotional Intelligence in the current study;

SEA 1 I recognise my emotions and their effects

SEA2 I know my strengths and limitations

SEA3 I have a strong sense of myself worth and capabilities

SEM1 I keep my disruptive emotions and impulses in check

SEM2 I maintain integrity and act congruently with my values

SEM3 I am flexible in handling change

SEM4 I strive to improve or meet standards of excellence

SEM5 I readily act on opportunities

SEM6 I am persistent in pursuing goals despite obstacles and set backs

SOA1 I sense others' feelings and perspectives and take active interest in their concerns

SOA2 I read groups' emotional currents and power relationships

SOA3 I anticipate, recognise and meet customers' needs

RM1 I sense others' development needs and bolster their abilities

RM2 I inspire and guide individuals and groups

RM3 I initiate and manage change successfully

RM4 I wield effective tactics for persuasion

RM5 I negotiate and resolve disputes/disagreements

RM6 I work with others towards shared goals and created group synergy in pursuing collective goals

RM7 I normally send clear and convincing messages

\section{The items used to measure Cross-cultural Adjustment;}

GA1 I have adjusted to the non-work aspects of the foreign country (e.g. housing, food, healthcare, shopping)

GA2 I overcame the culture shock that may distract me from adjusting to the culture of the country of assignment

WA1 I have adjusted to the level of responsibility associated with my job assignment

WA2 I have gained knowledge and expertise about the foreign country's operations, markets, customers and business practices

IA1 I have established and maintained relationship with the local staff

IA2 I interact with host nationals very well outside of work 


\section{REFERENCES}

Alon, I. and Higgins, J.M. (2005) Global leadership success through emotional and cultural intelligences. Business Horizons, 48(6), 501-512.

Andersen, P. A. \& Guerrero, L. K. (Eds.) (1998) Handbook of Communication and Emotion: Research, Theory, Applications, and Contexts. San Diego: Academic Press.

Anderson, J. \& Gerbing, D. (1988) Structural equation modelling in practice: A review and recommended two-step approach. Psychological Bulletin. 103(3), 411-423.

Ashkanasy, N.M. \& Daus, C.S. (2005) Rumors of the death of emotional intelligence in organizational behavior are vastly exaggerated. Journal of Organizational Behavior, 26, 441-52.

Avril, A. B. \& Magnini, V. P. (2007) A holistic approach to expatriate success. International Journal of Contemporary Hospitality Management, 19(1), 53-64.

Bar-On, R., (2000). Emotional and social intelligence: Insights from the Emotional Quotient Inventory (EQ-i). In R. Bar-On \& J.D.A. Parker (Eds.), Handbook of emotional intelligence (pp. 363-388). San Francisco: Jossey-Bass.

Bhaskar-Srinivas, P., Harrison, D. A., Shaffer, M. A., \& Luk, D. M. (2005) Input based and time based models of international adjustment: Meta-Analytic evidence and theoretical extensions. Academy of Management Journal, 48(2), 257-28.

Bhawuk, D. P. S., \& Brislin, R. (1992) The measurement of intercultural sensitivity using the concepts of individualism and collectivism. International Journal of Intercultural Relations, 16, 413-436.

Black, S. J. \& Stephens, K. G. (1989) The influence of the spouse on American expatriate adjustment in overseas assignments. Journal of Management, 15, 529-544.

Black, S. J., Mendenhall, M., \& Oddou, G. (1991) Toward a comprehensive model of international adjustment: an integration of multiple theoretical perspectives. Academy of Management Review, 16, 291-317.

Bonache, J., Brewster, C., \& Suutari, V. (2001) Expatriation: A Developing Research Agenda. Thunderbird International Business Review, 43, 3-20.

Bryman, A. \& Cramer, D. (2002) Quantative Data Analysis with SPSS Release 10 for Windows. 2nd ed. s.l.:Taylor and Francis.

Butler, C. and Chinowsky, P.S. (2006) Emotional intelligence and leadership behaviour in construction executives. Journal of Management in Engineering, 22 (3), 119-125.

Caligiuri, P. M. (1997) Assessing expatriate success: Beyond just "being there". In: Z. Aycan, ed. New approaches to employee management, Vol. 4: Expatriate management: Theory and research. Stamford: JAI Press Inc., pp. 117-140.

Caligiuri, P. (2000) Selecting expatriates for personality characteristics: a moderating effect of personality on the relationship between host international contact and cross-cultural adjustment. Management International Review, 40, 161-180.

Cherniss, C. \& Goleman, D. (2001). An EI-based theory of performance. In: C. Cherniss \& D. Goleman, eds. The Emotionally Intelligent Workplace. San Francisco: JosseyBass, pp. 2744.

Chew, J. (2004) Managing MNC Expatriates through Crises: A Challenge for International Human Resource Management. Research and Practice in Human Resource Management, 12(2), 1-30. 
Constantine, M. G., Okazaki, K., \& Utsey, S. O. (2004) Self-concealment, social efficacy, acculturative stress and depression in African, Asian and Latin America international college students. American Journal of Orthopsychiatry, 74 (3), 230-241.

Crowne, K. A. (2013) Cultural exposure, emotional intelligence, and cultural intelligence: An exploratory study. International Journal of Cross Cultural Management, 13(1), 5-22.

Dobson, P. J. (2002) Critical realism and information systems research: why bother with philosophy?. Information Research, 7(2).

Dolan, S.L. \& Kawamura, K. M. (2015) Cross-cultural Competence: A field guide for developing global leaders and managers. Bingley: Emerald.

Dowling, P. J., Welch, D. E., \& Schuler, R. S. (2004) International human resource management: Managing people in an international context (4th ed.). Cincinnati, $\mathrm{OH}$ : South Western College Publishing, ITP.

Earley, C. \& Ang, S. (2003) Cultural intelligence individual interactions across cultures. Stanford California: Stanford University Press.

Emmerling, R. J. \& Boyatzis, R. E. (2012). Emotional and social intelligence competencies: cross cultural implications. Cross Cultural Management: An International Journal, 19 (1), $4-18$.

Firth, A. (2015) Building leadership capability in the construction sector. White paper: Roffey Park Institute.

Gabel, R. S., Dolan, S. L., \& Cerdin, J. L. (2005) Emotional intelligence as predictor of cultural adjustment for success in global assignments. Career Development International, 10(5), 375-395.

Gabel-Shemueli, R. \& Dolan, S. (2011) Do emotions matter?: The role of emotional intelligence competences in cross-cultural adjustment for international assignment. Management Research: The Journal of the Iberoamerican Academy of Management, 9(3), 207 - 229.

Garonzik, R., Brockner, J., \& Siegel, P. A. (2000) Identifying international assignees at risk for premature departure: The interactive effect of outcome favorability and procedural fairness. Journal of Applied Psychology, 85, 13-20.

Goleman, D. (1995) Emotional Intelligence: Why it can Matter More Than IQ. New York, NY: Bantam Books.

Goleman, D. (1998) Working with Emotional Intelligence, Bantam Books, New York, NY.

Grandzol, J.R., Gershon, M. (1998) A survey instrument for standardizing TQM Modelling research. International Journal of Quality Science, 3(1), 80-105.

Greene, J. C. \& Caracelli, V. J. (1997) Defining and Describing the Paradigm Issue in Mixed Method Evaluation. In: C. J. Greene \& V. J. Caracelli, eds. Mixed-Method Evaluation: The Challenges and Benefits of Integrating Diverse Paradigms. San Francisco: Jossey-Bass Publishers, pp. 5-17.

Hair, J F., Black, W C., Babin, B., Anderson, R., Tatham, R. (2006) Multivariate Data Analysis. 6th ed. Upper Saddle River, NJ: Prentice Hall.

Hair, J. J. F., Anderson, R. E., Tatham, R. L., \& C, B. W. (1998) Multivariate data analysis. Englewood Cliffs: Prentice-Hall.

Hall, R. (2008) Applied social research: planning, designing and conducting real world research. London: Sage Publications.

Harrison, D. A. \& Shaffer, M. A. (2005) Mapping the criterion space for expatriate success: taskand relationship-based performance, effort and adaptation. International Journal of Human Resource Management, 16(8), 1454-74. 
Haslberger, A. (2008) Expatriate Adjustment. In C. Brewster, M. Dickmann, P. Sparrow (eds) International Human Resource Management. 130-149. Routledge.

Hemmasi, M., Downes, M., \& Varner, I. I. (2010) An empirically-derived multidimensional measure of expatriate success: reconciling the discord. The International Journal of Human Resource Management, 21(7), 982-998.

Higgs, M. \& McGuire, M. (20010 Emotional Intelligence and Culture: an Exploration of the Relationship between Individual. Working Paper Series. Henley Management College.

Hulland, J. (1999) Use of partial least square (PLS) in strategic management research: a review of four recent studies, Strategic Management Journal, 20(2), 195-204.

Islam, M.M.D., Faniran, O., and Olusegun, (2005) Structural equation model of project planning effectiveness. Construction Management and Economics, 23, 215-223.

Jamieson, S. (2004) Likert scales: how to abuse them, Blackwell Publishing Ltd. Medical Education, 38, 1212-1218.

Jassawalla, A., Truglia, C., \& Garvey, J. (2004) Cross cultural conflict and expatriate managers adjustment: An exploratory study. Management Decision, 42 (7), 837-849.

Jordan, P. J., Ashkanasy, N. M., Ha“rtel, C. E. J. \& Hooper, G. S. (2002) Workgroup emotional intelligence: scale development and relationship to team process effectiveness and goal focus. Human Resource Management Review, 12(2), 195-214.

Kayes, D. C., Kayes, A. B., \& Yamazaki, Y. (2005) Essential competencies for cross-cultural knowledge absorption. Journal of Managerial Psychology, 20 (7), 578-89.

Kenny, D.A., (2012) Structural Equation Modelling. [Online] Available at: http://davidakenny. net/cm/causa lm. htm [Accessed 25 October 2012].

Kittler M .G., Rygl, D., Mackinnon, A., and Wiedemann, K. (2011) Work role and work adjustment in emerging markets: A study of German expatriates in CEE countries and Russia. Cross Cultural Management: An International Journal, 18(2), 165-184.

Kline, R. B. (1998) Principles and practice of structural equation modeling. New York: Guilford Press.

Konanahalli, A., Oyedele, L., Spillane, J.P., Coates, R., von Meding, J., and Ebohon, J. (2014) Cross-cultural intelligence (CQ): It's impact on British expatriate adjustment on international construction projects. International Journal of Managing Projects in Business, 7(3), 423-448.

Konanahalli, A., Oyedele, L., von Meding, J., Spillane, and Coates, R. (2012) International Projects and Cross-Cultural Adjustment of British Expatriates in Middle East: A Qualitative Investigation of Influencing Factors. Australasian Journal of Construction Economics and Building, 12(3), 31-54.

Koveshnikov, A., Wechtler, H., and Dejouxc, C. (2014) Cross-cultural adjustment of expatriates: The role of emotional intelligence and gender. Journal of World Business, 49(3), 362-371.

Kraimer, L. M., \& Wayne, J. S. (2004) An expamination of percieved organisational support as a multiple dimensional construct in the context of an expatriate assignment. Journal of management, 30(2), 209-37.

Lievens, F., Harris, M.M., Keer, E.V., and Bisqueret, C. (2003) Predicting cross-cultural training performance: The validity of personality, cognitive ability, and dimensions measured by an assessment centre and a behaviour description interview. Journal of Applied Psychology, 88, 476-489.

Lii, S. Y., \& Wong, S. Y. (20080 The antecedents of overseas adjustment and commitment of expatriates. The International Journal of Human Resource Management, 19(2), 296-313. 
Lillis, M. P., \& Tian, R. G. (2009) Cross-cultural communication and emotional intelligence Inferences from case studies of gender diverse groups. Marketing Intelligence \& Planning, 27(3), 428-438.

Lin, Y.C., Chen, A. S.Y., \& Song, Y.C. (2012). Does your intelligence help to survive in a foreign jungle? The effects of cultural intelligence and emotional intelligence on crosscultural adjustment. International Journal of Intercultural Relations, 36(4), 541-552.

Lindebaum, D., \& Fielden, S.L. (2011) It's good to be angry: enacting anger in construction project management to achieve perceived leader effectiveness. Human Relations, 64(3), 437-58.

Lindebaum, D., \& Jordan, P.J. (2012) Relevant but exaggerated: The effects of Emotional Intelligence on project manager performance in construction. Construction Management and Economics, 30(7), 575-583.

Liu, C. H., \& Lee, H.W. (2008) A proposed model of expatriates in multinational corporations, Cross Cultural Management: An International Journal, 15(2), 176 - 193.

Lloyd, S., \& Härtel, C. E. J. (2003) The intercultural competencies required for inclusive and effective culturally diverse work, s.l.: Monash University, Faculty of Business and economics.

Mammadov, S., \& Poss, L. (2010) Forward foundations: Where will engineering and construction companies explore growth, and what will it mean for talent strategy? 27(Fluor Corporation). In: W. Owen, ed. International Assignment Perspectives: Critical issues facing the globally mobile work force. s.1.:PriceWaterCoopers, pp. 27-33.

Mathews, G., Zeidner, M., \& Roberts, R. D. (2002) Emotional Intelligence: Science and Myth Bradford Book. Cambridge, Massachusetts, London, England: MIT Press.

Mayer, J. D., \& Salovey, P. (1995) Emotional intelligence and the construction and regulation of feelings. Applied and Preventive Psychology, 4, 197-208.

Mayer, J. D., Caruso, D. R., \& Salovey, P. (1999) Emotional intelligence meets traditional standards for an intelligence. Intelligence, 27, 267-298.

McEvoy, G.M., and Parker, B. (1995) Expatriate Adjustment: Causes and Consequences. In Selmer, J. (ed.) Expatriate Management: New Ideas for International Business. Westport,CT: Quorum Books.

Min, H., Magnini V. P., Singal, M. (2013) Perceived corporate training investment as a driver of expatriate adjustment. International Journal of Contemporary Hospitality Management, 25 (5), 740-759.

Mol, S. T., Born, M. P., Willemson, M. E., \& Van der Molen, H. (2005) Predicting expatriate job performance for selection purposes: a quantitative review. Journal of Cross cultural Psychology, 36(5), 590-620.

Moran, R. T., \& Riesenberger, J. R. (1994) The Global Challenge: Building the New World wide Enterprise. UK: McGraw-Hill.

Musten, M. S., \& Titarenko, D. (2003) Emotional Intelligence as a tool for successful expatriate management, s.l.: University of Southern Denmark.

Nunnally, J. C. (1967) Psychometric Methods. New York: McGraw Hill.

Nunnally, J. (1978) Psychometric Theory. New York, NY: McGraw-Hill.

O'Boyle, E.H., Humphrey, R.H., Pollack, J.M., Hawver, T.H., and Story, P.A. (2010) The relation between emotional intelligence and job performance: a meta-analysis. Journal of Organizational Behavior, 32(5), 788-818. 
Oberg, K. (1960) Culture shock: Adjustment to New Cultural Environments. Practical Anthropology, 7, 177-182.

Palthe, J. (2004) The relative importance of antecedents to cross-cultural adjustment: Implications for managing a global workforce. International Journal of Intercultural Relations, 28, 37-59.

Peltokorpi, V., \& Froese, F. J. (2009) Organisational expatriates and self-initiated expatriates: who adjusts better to work and life in Japan. International Journal of Human Resource Management, 20(5), 1096-1112.

Podsakoff, P., Mackenzie, S., Lee, J., and Podsakoff, N. (2003) Common method biases in behavioral research: a critical review of the literature and recommended remedies. Journal of Applied Psychology, 88, 879-903.

Pryke, S., Smyth, H. (2006) The Management of Complex Projects: A Relationship Approach. Blackwell Publishing.

Puck, J. F., Mohr, A. T., \& Rygl, D. (2008) An empirical analysis of managers' adjustment to working in multi-national project teams in the pipeline and plant construction sector. The International Journal of Human Resource Management, 19(12), 2252-2267.

Raine-Eudy, R. (2000) Using structural equation modelling to test for different reliability and validity: An empirical demonstration. Structural Equation Modelling, 7, 124-141.

Ramgutty-Wong, A., \& Dusoye, I. (2011) Assessing cultural adaptation competencies at senior executive level: the case of expatriates in Mauritius. Mauritius, International Conference on International Trade and Investment.

Salovey, P., \& Mayer, J. (1990). Emotional intelligence. Imagination, cognition, and personality, 9(3), pp. 185-211.

Santosoa, J., and Loosemore, M. (2013) Expatriate management in Australian multinational enterprises. Construction Management and Economics, 31(11), 1098-1109.

Scullion, H., \& Brewster, C. (2001) The Management of Expatriates: Messages from Europe?. Journal of World Business, 36, 346-365.

Shimoni, T., Ronen, S., \& Roziner, Shaffer, M.A., Harrison, D.A., and Gilley, K.M. (1999), 'Dimensions, Determinants, and Differences in the Expatriate Adjustment Process,' Journal of International Business Studies, 30(3), 557-581.

Shin, S. J., Morgeson, F.P., \& and Campion, M. A. (2003) Expatriate Assignments: Understanding the Skill, Ability, Personality, and Behavioral Requirements of Working Abroad, s.l.: Purdue CIBER Working Papers.

Sivo, S.A., Fan, X., Witta, E.L., and Willse, J.T. (2006) The search for "optimal" cut-off properties: fit index criteria in structural equation modelling. The Journal of Experimental Education, 74(3), 267-288.

Spreen M. (1992) Rare populations, hidden populations and link racing designs: what and why? Bulletin Methodologie Sociologique, 36, 34-58.

Stroh, L., Black, J., Mendenhall, M., \& Gregersen, H. (2005) International Assignments: An Integration of Strategy, Research, and Practice. Mahwah, NJ: Lawrence Erlbaum Associates.

Sunindijo, R., Hadikusumo, B., and Ogunlana, S. (2007) Emotional Intelligence and Leadership Styles in Construction Project Management. Journal of Management in Engineering, 23 (4), 166-170. 
Susanto, E., \& Rostiani, R. (2012) Enhancing Cross-Cultural Training Efficacy on Expatriate Adjustment through Emotional Intelligence and Social Capital. Gadjah Mada International Journal of Business, 14(2), pp.123 - 137.

Tan, J. A. C., Hartel, C. E. J., Panipucci, D., \& Strybosch, V. E. (2005) The effect of emotions in cross-cultural expatriate experiences. Cross Cultural Management: An International Journal, 12(2), 4-15.

Teddlie, C., Yu, F. (2007) Mixed Methods Sampling -A Typology with Examples. Journal of Mixed Methods Research, 1(1), 77-100.

Torbiorn, I. (1982) Living abroad: Personal Adjustment and Personnel Policy in the Overseas Setting. New York: Wiley.

Tung, R.L. (1987) Expatriate Assignments: Enhancing Success and Minimizing Failure, Academy of Management Executive, 1, 117-126.

Waxin, M-F., \& Panaccio, A. (2005) Cross-cultural training to facilitate expatriate adjustment: It works!. Personnel Review, 34, 51-67.

Wechtler, H., Koveshnikov, A., \& Dejoux, C. (2015) Just like a fine wine? Age, emotional intelligence, and cross-cultural adjustment. International Business Review, 24, 409-418.

Wheeldon, J. P. (2010) Mapping mixed methods research: Methods, measures, and meaning. Journal of Mixed Methods Research, 4(2), 87-102.

Yamazaki, Y., \& Kayes, D. C. (2004) An experiential approach to cross cultural learning: A review and integration of competencies for successful expatriate adaptation. Academy of management learning and education, 3(4), 362-379.

Zainol, H., Abdul Aziz, A.R. (2010) Personal Adjustment for expatriate Malaysian project executives in host country. International Journal of Arts and Sciences. 3(13), $213-230$.

Zainol, H., Tambi A.M.A., and Abdul-Aziz, A-R. (2013) The Preparedness of Malaysian Multinational Construction Companies (MNCCs) in Providing Pre-Departure and NonTechnical Trainings for Their Expatriates. World Applied Sciences Journal, 25 (3), 391398. 